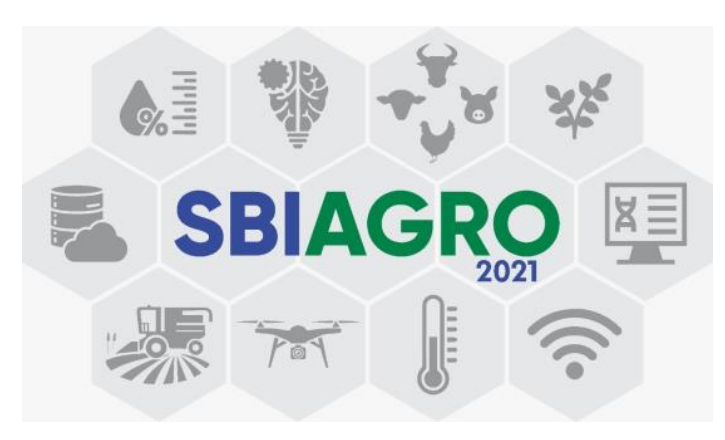

\title{
Análise bibliométrica da produção científica da EMBRAPA na Web of Science
}

\author{
Alexandre D. Alves \\ Centro de Matemática, Computação e Cognição - Universidade Federal do ABC (UFABC) \\ Av. dos Estados, 5001 - Bairro Santa Terezinha - Santo André - SP - Brasil \\ alexandre.donizeti@ufabc.edu.br
}

\begin{abstract}
This article aims to present a bibliometric analysis of the scientific production of authors linked to EMBRAPA considering the articles published in journals indexed in the Web of Science from 1974 to 2021. During this period, 27,089 articles were published in collaboration with co-authors from 140 different countries, being the main collaboration with co-authors from the United States.

Resumo. Este artigo tem como objetivo apresentar uma análise bibliométrica da produção científica dos autores vinculados à EMBRAPA considerando os artigos publicados em periódicos indexados na Web of Science no período de 1974 a 2021. Nesse periodo foram publicados 27.089 artigos em colaboração com coautores de 140 países diferentes, sendo a principal colaboração com coautores dos Estados Unidos.
\end{abstract}

\section{Introdução}

A Empresa Brasileira de Pesquisa Agropecuária (EMBRAPA) é uma instituição pública de pesquisa vinculada ao Ministério da Agricultura, Pecuária e Abastecimento. Foi criada em 26 de abril de 1973 e é uma empresa de inovação tecnológica focada na geração de conhecimento e tecnologia para a agricultura e pecuária brasileira. Ao longo desses anos, a agropecuária brasileira se tornou, com certeza, uma das mais eficientes e sustentáveis do planeta.

A produção científica da EMBRAPA ocupa lugar de destaque entre as instituições do País considerando os artigos publicados em periódicos indexados na Web of Science (WoS). A WoS é uma base de dados reconhecida mundialmente por toda a comunidade científica pela sua amplitude. Nessa base, a EMBRAPA ocupa atualmente a oitava posição com $27.089(3,42 \%)$ artigos, ficando atrás apenas das seguintes instituições: USP (176.573; 22,27\%), UNESP (61.451; 7,75\%), UNICAMP 
(60.826; 7,67\%), UFRJ (53.919; 6,80\%), UFRGS (44.294; 5,59\%), UFMG (41.097; $5,18 \%)$ e UNIFESP $(31.456 ; 3,97 \%)$.

Na revisão da literatura realizada de forma sistemática e sintética, constatou-se que há poucos trabalhos que analisam a produção científica da EMBRAPA na WoS (Penteado Filho e Avila, 2009a; Penteado Filho e Avila, 2009b; Penteado Filho e Avila, 2009c; Penteado Filho e Avila, 2010). Porém, esses trabalhos consideraram a produção científica no período de 1977 a 2006. Há também um trabalho recente que considerou a produção científica da EMBRAPA na base Scopus (Irizaga e Vanz, 2021).

O objetivo deste trabalho é analisar a produção científica dos autores vinculados à EMBRAPA a partir das informações sobre os artigos publicados em periódicos indexados na WoS no período de 1974 a 2021. Este estudo considera indicadores bibliométricos baseados em coautoria e citações, incluindo distribuição geográfica, análise temporal dos periódicos e palavras-chaves mais usadas pelos autores vinculados à EMBRAPA.

O mapeamento da produção científica de uma instituição permite contar um pouco de sua própria história, assim como pode indicar o perfil de colaboração científica nas publicações dos pesquisadores dessa instituição. Conhecer esse perfil permite definir estratégias de incentivo para a instituição.

Este texto está organizado da seguinte maneira: na Seção 2 é descrito como foram coletados os dados de interesse. Também são destacadas as ferramentas usadas na elaboração deste trabalho. Na Seção 3 são apresentados os principais resultados, discutindo alguns pontos importantes. Finalmente, na Seção 4 são apresentadas as considerações finais.

\section{Materiais e Métodos}

Inicialmente, foi realizada uma busca avançada por artigos da organização consolidada "Empresa Brasileira de Pesquisa Agropecuaria (EMBRAPA)" publicados em periódicos indexados na WoS que engloba as diversas formas que uma instituição foi informada naquela base. Para este trabalho foram considerados apenas os seguintes índices de citação: Science Citation Index Expanded (SCI-EXPANDED), Social Sciences Citation Index (SSCI) e Arts \& Humanities Citation Index (A\&HCI). Assim, foi possível obter a produção científica de autores vinculados à EMBRAPA a partir de informações das publicações (artigos) indexadas na WoS.

O total de artigos encontrados foi 27.089. A partir disso, foi possível baixar os registros desses artigos. Em seguida, foi feita a extração e os dados foram armazenados em um banco de dados. Todo esse processo, brevemente aqui descrito, foi realizado no dia 3 de setembro de 2021. As seguintes informações foram obtidas para este trabalho: artigos (id, título, ano, periódico, total de autores, total de citações, afiliações e palavraschave). $\mathrm{O}$ acesso a essas informações foi feito através do Portal de Periódicos da CAPES.

O mapa apresentado neste trabalho foi gerado usando a ferramenta GPS Visualizer (acessível em http://www.gpsvisualizer.com). Os mapas de visualização foram gerados usando a ferramenta VOSviewer (Van Eck e Waltman, 2010), que permite a construção e visualização de redes bibliométricas. $\mathrm{O}$ acesso ao fator de 
impacto (FI) de 2020 no Journal Citation Reports ${ }^{\circledR}\left(\mathrm{JCR}^{\circledR}\right)$ também foi feito através do Portal de Periódicos da CAPES.

\section{Resultados e Discussões}

De acordo com os registros da WoS, o primeiro artigo da EMBRAPA foi o de Turnipseed et al. (1974), no periódico "Journal of Economic Entomology", e o mais citado é o artigo de Aljanabi e Martinez (1997), publicado no periódico "Nucleic Acids Research", com 1.752 citações. Desde o primeiro artigo registrado na WoS até 03/09/2021, os autores vinculados à EMBRAPA publicaram 27.089 artigos em periódicos indexados nesta base.

Na Figura 1 apresenta-se o número de artigos no período de 1974 a 2021 e a média de autores por ano. Nos últimos 20 anos o número de artigos aumentou quase cinco vezes, enquanto a média de autores dobrou, chegando a 8,03 autores por artigo em 2020. Ao longo dos anos a média de autores foi 6,04. Com relação a autoria dentre os 27.089 artigos, $455(1,68 \%)$ foram publicados por um único autor, enquanto 26.634 $(98,32 \%)$ foram em coautoria. Do total de artigos em coautoria, $1.789(6,60 \%)$ artigos foram publicados por dois autores, $3.058(11,29 \%)$ por três autores e $21.787(80,43 \%)$ por 4 ou mais autores. O artigo com mais autores (729) foi publicado por Kattge et al. (2020), no periódico "Global Change Biology".

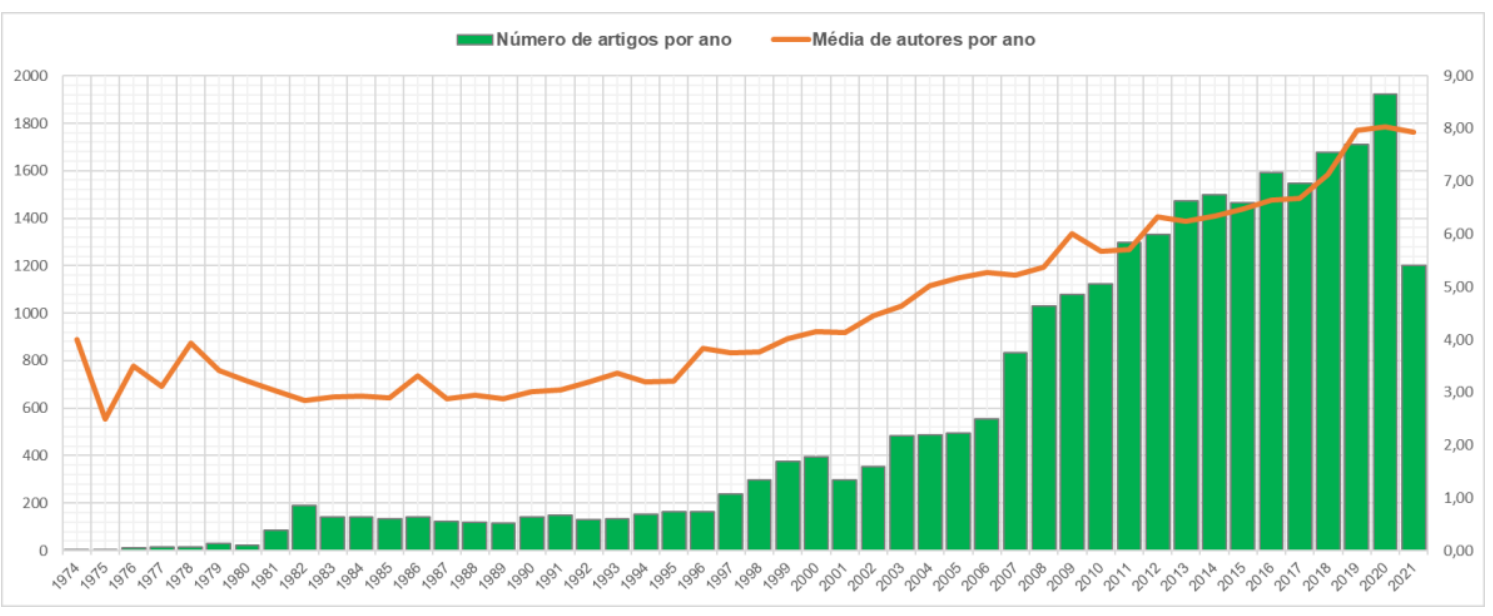

Figura 1. Número de artigos publicados pelos autores vinculados à EMBRAPA em periódicos indexados na WoS e média de autores por ano

Do total de 27.089 artigos publicados em periódicos, 3.634 (13,42\%) ainda não foram citados. Porém, $3.121(85,88 \%)$ desses artigos foram publicados a partir de 2020. Os outros $23.455(86,58 \%)$ artigos foram citados por 396.764 artigos, com uma média de 16,92 citações por artigo. Desse total, 446 foram citados mais de 100 vezes e 4 artigos foram citados mais de 1.000 vezes.

Para publicar esses 27.089 artigos, os autores vinculados à EMBRAPA colaboraram com autores de outros 140 países. É importante destacar que um determinado artigo pode ser contabilizado por mais de um país. Isso se deve ao fato de que a WoS faz a contagem contabilizando todas as afiliações informadas nos artigos (Almeida e Guimarães, 2013). A Figura 2 apresenta a distribuição geográfica dos coautores que publicaram com autores vinculados à EMBRAPA. São destacados na cor 
"cinza" os países $(44 ; 31,43 \%)$ em que houve menos de cinco colaborações. As principais colaborações foram com os Estados Unidos (2.698), França (776) e Inglaterra (556).

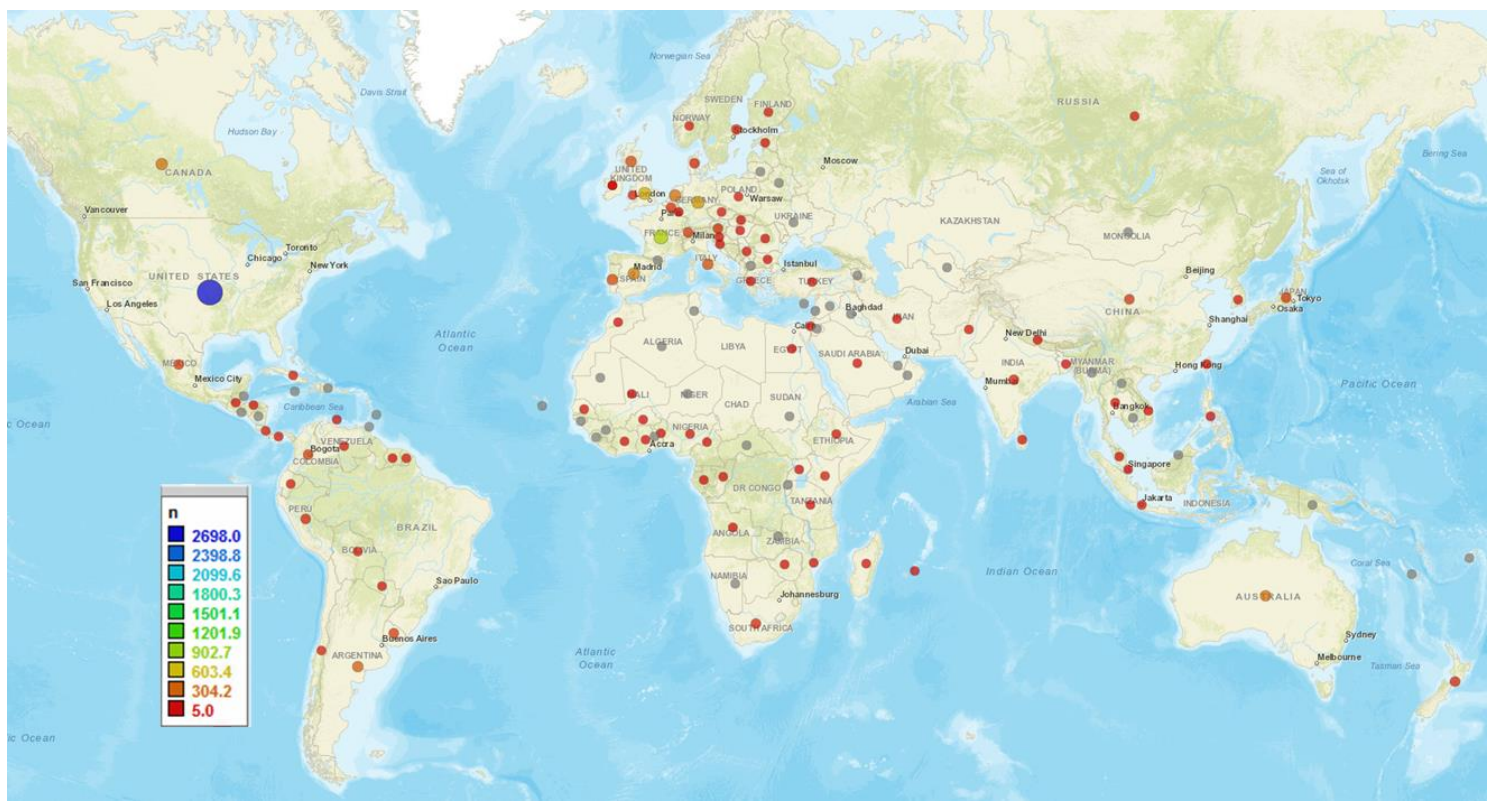

Figura 2. Distribuição geográfica dos coautores que publicaram artigos com autores vinculados à EMBRAPA em periódicos indexados na WoS no período de 1974 a 2021. Os 140 países identificados estão destacados por cores de acordo com o número de documentos em colaboração. Os países com menos de 5 colaborações estão destacados na cor cinza

Essas colaborações também são destacadas no mapa de visualização da rede de coautorias por país de origem ilustrado na Figura 3. $75(53,19 \%)$ países com pelo menos 10 publicações no período de 1974 a 2021 foram incluídos no mapa de visualização e estão agrupados em 6 clusters. A espessura de uma relação entre quaisquer dois países é um indicativo da importância da coautoria (ou seja, colaboração). É possível observar a posição de destaque do Brasil, representado no cluster azul, juntamente com outros 7 países das Américas e a Espanha. Neste mesmo cluster também é curioso observar que Honduras se relaciona apenas com o Brasil. O maior cluster, com 49 países, é representado na cor vermelha, sendo a Austrália o país com o maior número de artigos. 


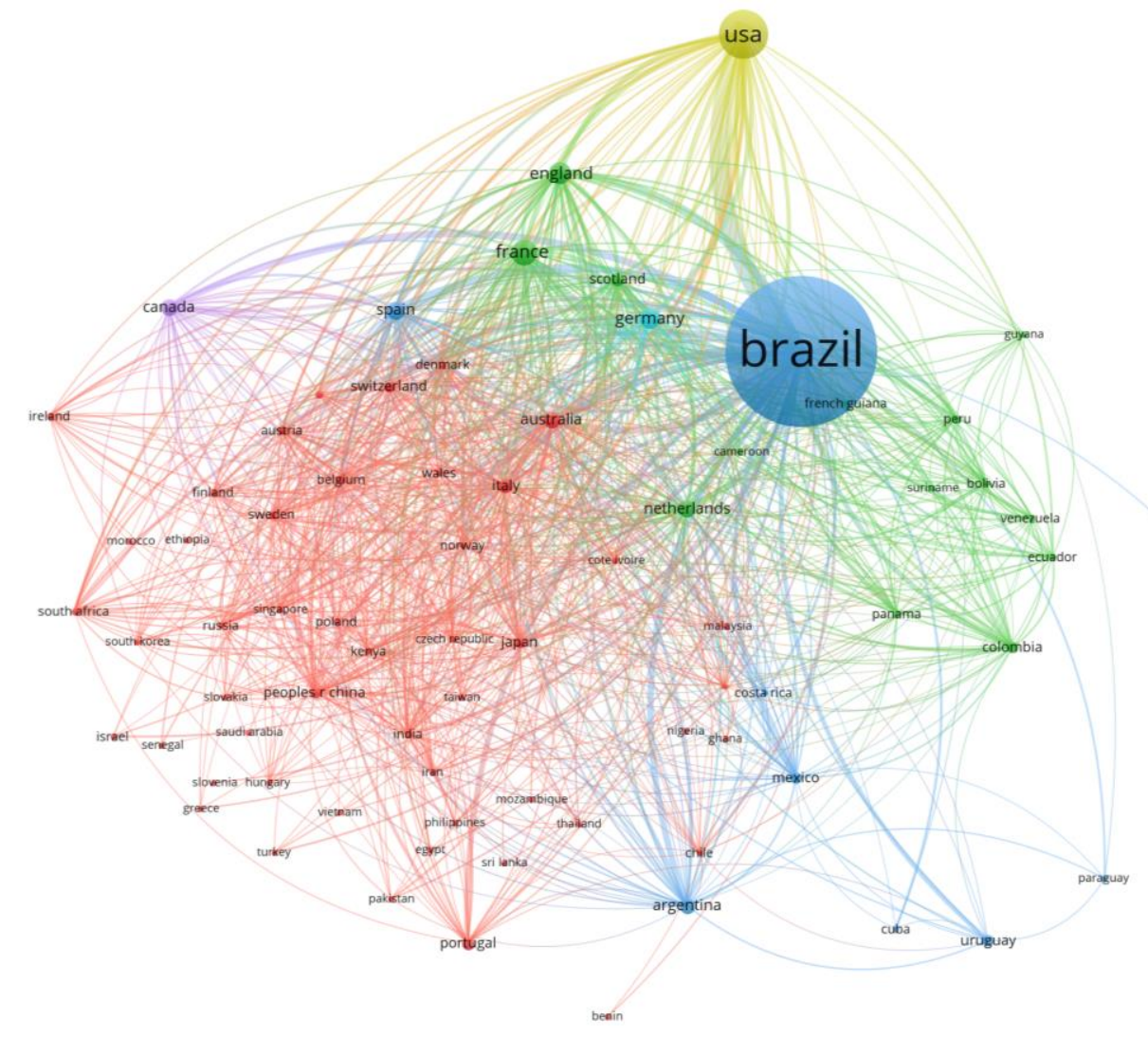

Figura 3. Mapa de visualização da rede de coautorias por país de origem de acordo com a afiliação informada nos artigos publicados por autores vinculados à EMBRAPA em periódicos indexados na WoS no período de 1974 a 2021. A relação entre os países é determinada pelo número de documentos em colaboração. Entre os 141 países identificados, 75 tinham pelo menos 10 documentos e estão agrupados em 6 clusters

A Tabela 1 apresenta a distribuição dos 5 periódicos mais usados por período pelos autores vinculados à EMBRAPA para publicação de artigos em periódicos indexados na WoS. Percebe-se que em todos os períodos há maior divulgação de pesquisas em periódicos brasileiros. É interessante também observar que no período de 2011 a 2020, o periódico "PLOS ONE" passou a ser um dos mais usados, embora o periódico tenha sido criado em 2009. O periódico "Pesquisa Agropecuária Brasileira" foi o mais usado em quase todos os períodos analisados. Porém, no ano de 2021 (ainda incompleto) não conste na relação dos 5 periódicos mais usados. Nota-se também que nos últimos dois anos há uma predileção pelo periódico "Scientific Reports", em detrimento ao periódico "PLOS ONE". Talvez o FI tenha influenciado nessa mudança.

O periódico "Semina: Ciências Agrárias" foi o mais usado nos últimos 2 anos e também está entre os mais usados no período de 2011 a 2020. O periódico "Ciência Rural" também foi destaque nesses mesmos períodos. O número de periódicos distintos usados no período de 2011 a 2020 aumentou significativamente $(71,80 \%)$ em relação à década anterior. Isso também impactou na porcentagem do periódico mais usado, sendo quase 3 vezes menor. É curioso que só afetou a porcentagem do periódico mais usado. 
Tabela 1. Distribuição dos periódicos indexados na WoS mais usados pelos autores vinculados à EMBRAPA

\begin{tabular}{|c|c|c|c|}
\hline ISSN & Periódico & Artigos $(\%)$ & FI 2020 \\
\hline \multicolumn{4}{|c|}{1974 a 2021 (27.089 artigos) [2.005 periódicos] } \\
\hline $0100-204 X$ & Pesquisa Agropecuária Brasileira & $3.324(12,27)$ & 1,088 \\
\hline $0103-8478$ & Ciência Rural & $615(2,27)$ & 0,803 \\
\hline $0100-2945$ & Revista Brasileira de Fruticultura & $517(1,91)$ & 0,912 \\
\hline 0100-0683 & Revista Brasileira de Ciência do Solo & $472(1,74)$ & 1,683 \\
\hline $1676-546 \mathrm{X}$ & Semina: Ciências Agrárias & $429(1,58)$ & 0,564 \\
\hline \multicolumn{4}{|c|}{2001 a 2010 (6.737 artigos) [922 periódicos] } \\
\hline $0100-204 X$ & Pesquisa Agropecuária Brasileira & $896(13,30)$ & 1,088 \\
\hline $1413-7054$ & Ciência e Agrotecnologia & $252(3,74)$ & 1,390 \\
\hline $0100-0683$ & Revista Brasileira de Ciência do Solo & $201(2,98)$ & 1,683 \\
\hline $0100-2945$ & 9 Revista Brasileira de Fruticultura & $182(2,70)$ & 0,912 \\
\hline $1806-9290$ & Revista Brasileira de Zootecnia & $180(2,67)$ & 0,967 \\
\hline \multicolumn{4}{|c|}{2011 a 2020 (15.513 artigos) [1.584 periódicos] } \\
\hline 0100-204X & Pesquisa Agropecuária Brasileira & $713(4,60)$ & 1,088 \\
\hline $0103-8478$ & Ciência Rural & $436(2,81)$ & 0,803 \\
\hline $1676-546 X$ & Semina: Ciências Agrárias & $373(2,40)$ & 0,564 \\
\hline $0100-2945$ & Revista Brasileira de Fruticultura & $318(2,05)$ & 0,912 \\
\hline $0100-0683$ & Revista Brasileira de Ciência do Solo & $270(1,74)$ & 1,683 \\
\hline $1932-6203$ & 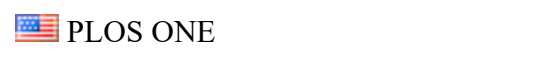 & $270(1,74)$ & 3,240 \\
\hline \multicolumn{4}{|c|}{2020 (1.921 artigos) [653 periódicos] } \\
\hline $1676-546 \mathrm{X}$ & Semina: Ciências Agrárias & $40(2,08)$ & 0,564 \\
\hline $0100-204 X$ & Pesquisa Agropecuária Brasileira & $38(1,98)$ & 1,088 \\
\hline $1932-6203$ & 笋 PLOS ONE & $32(1,67)$ & 3,240 \\
\hline $2045-2322$ & Scientific Reports & $29(1,51)$ & 4,379 \\
\hline $0103-8478$ & Ciência Rural & $25(1,30)$ & 0,803 \\
\hline \multicolumn{4}{|c|}{2021 (1.200 artigos) [490 periódicos] } \\
\hline $1676-546 X$ & Semina: Ciências Agrárias & $38(3,17)$ & 0,564 \\
\hline $2045-2322$ & Scientific Reports & $22(1,83)$ & 4,379 \\
\hline $1678-992 X$ & Scientia Agricola & $20(1,67)$ & 2,137 \\
\hline $0103-8478$ & Ciência Rural & $20(1,67)$ & 0,803 \\
\hline $0100-2945$ & Revista Brasileira de Fruticultura & $17(1,42)$ & 0,912 \\
\hline $1519-566 \mathrm{X}$ & Neotropical Entomology & $17(1,42)$ & 1,434 \\
\hline
\end{tabular}


A Figura 4 apresenta o mapa de visualização da rede de coautorias de acordo com as instituições informadas nas afiliações. Entre as 11.711 instituições identificadas, 131 tinham pelo menos 100 documentos e estão agrupadas em 7 clusters. A EMBRAPA e a USP ocupam posição de destaque no mapa de visualização devido ao número de documentos. Porém, a USP (130) e a Universidade Federal de Viçosa (129) se destacam em relação ao número de relacionamentos. A EMBRAPA, com 110 relacionamentos de colaboração, é prejudicada pois pode-se notar que há diferentes designações para a instituição representadas no mapa. Essa falta de padronização das afiliações dos autores vinculados à EMBRAPA na WoS inclusive já foi estudada por Penteado Filho e Fonseca Júnior (2017). Diante disso, a instituição publicou uma resolução normativa interna regulamentando a afiliação de seus pesquisadores em publicações nacionais e internacionais.

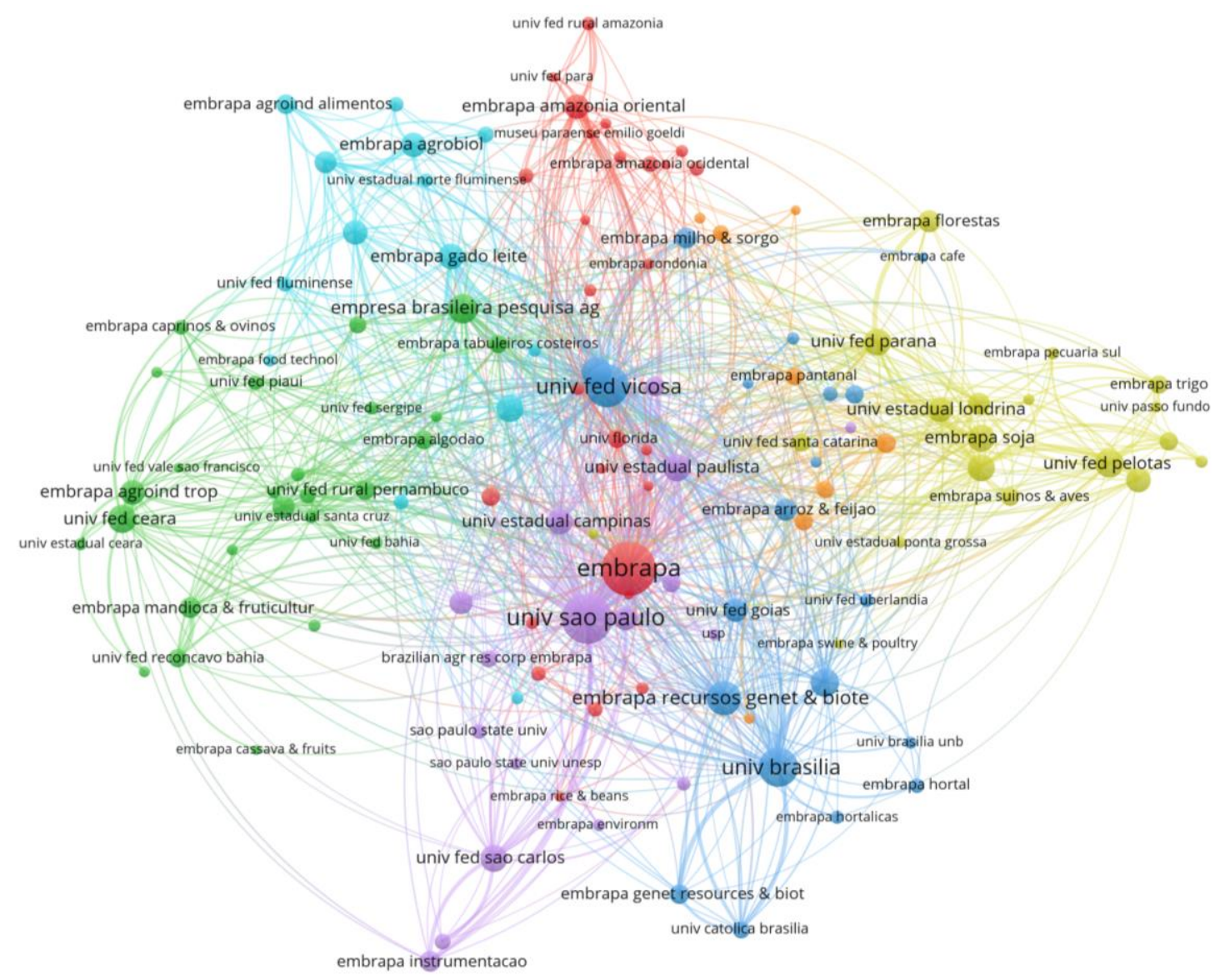

Figura 4. Mapa de visualização da rede de coautorias por instituição de origem de acordo com a afiliação informada nos artigos publicados por autores vinculados à EMBRAPA em periódicos indexados na WoS no período de 1974 a 2021. A relação entre as instituições é determinada pelo número de documentos em colaboração. Entre as 11.711 instituições identificadas, 131 tinham pelo menos 100 documentos e estão agrupadas em 7 clusters

Também foi realizada uma análise das palavras-chave mais usadas pelos autores vinculados à EMBRAPA, conforme ilustrado na Figura 5. No total de 27.089 artigos considerados neste trabalho foram identificadas 39.897 palavras-chave distintas, sendo que 175 foram usadas em pelo menos 50 documentos e estão agrupadas em 7 clusters. 
As palavras-chave mais usadas foram "glycine max" (458), "biological control" (439) e "Brazil" (414). É interessante que essas palavras-chave também foram as mais usadas em 2020. Em 2021, as palavras-chave mais usadas por enquanto foram "biological control", "phenolic compounds" e "sustainability". No mapa de visualização, a palavrachave "Brazil" se relaciona com 98 outras palavras-chave, enquanto "glycine max" e "biological control" se relacionam com 93 e 50 outras palavras-chave, respectivamente. É curioso que a palavra-chave "chitosan" não se relaciona com nenhuma outra.

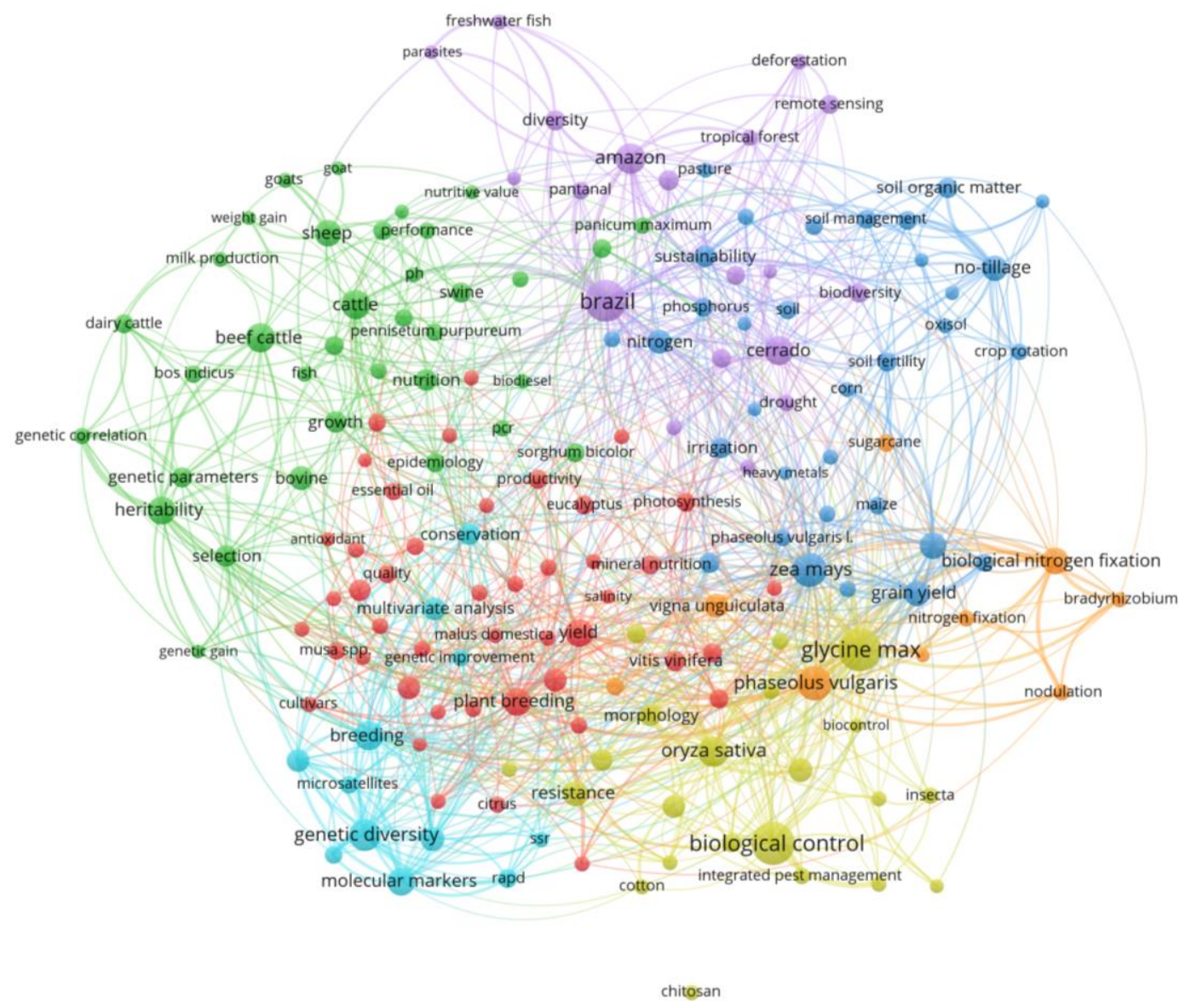

Figura 5. Mapa de visualização da rede de co-ocorrência de palavras-chave usadas em artigos publicados pelos autores vinculados à EMBRAPA em periódicos indexados na WoS no período de 1974 a 2021. A relação entre as palavras-chave é determinada pelo número de documentos em que ocorrem em conjunto. Entre as 39.897 palavras-chave identificadas, 175 foram usadas em pelo menos 50 documentos e estão agrupadas em 7 clusters

\section{Considerações Finais}

Neste trabalho foi apresentada uma análise bibliométrica da produção científica dos autores vinculados à EMBRAPA considerando os artigos publicados em periódicos indexados na WoS no período de 1974 a 2021. A produção científica da EMBRAPA aumentou significativamente $(130,27 \%)$ no período de 2011 a 2020 em relação ao período anterior de 2001 a 2010. No período de 1974 a 2021 foram publicados 27.089 artigos e mais de $85 \%$ dos artigos já foram citados, sendo que 446 desses artigos foram citados mais de 100 vezes e 4 foram citados mais de 1.000 vezes. Nesse período, a EMBRAPA colaborou com pesquisadores de 140 países diferentes, o que certamente 
contribuiu para aumentar o reconhecimento da instituição no cenário mundial. A média de autores foi de 6,04 autores por artigo. Entretanto, essa média vem aumentando, já sendo superior a 8 autores por artigo. Os artigos publicados pelos autores vinculados à EMBRAPA foram em sua maioria $(98,32 \%)$ em coautoria, sendo que mais de $80 \%$ foram publicados por 4 ou mais autores. A principal colaboração ocorreu com coautores dos Estados Unidos. Embora fique evidente uma predileção por periódicos brasileiros, isso vem mudando um pouco nos últimos anos. Recentemente, nota-se que periódicos internacionais e multidisciplinares como "PLOS ONE" e "Scientific Reports" têm sido bastante considerados pelos autores vinculados à EMBRAPA. Também é importante destacar a $8^{\mathrm{a}}$ posição que a EMBRAPA ocupa entre as instituições que mais publicaram artigos em periódicos indexados na WoS considerando a produção científica brasileira.

A análise da produção científica de uma instituição permite contar parte de sua própria história, assim como pode indicar o perfil de colaboração científica nas publicações dos seus pesquisadores, suas competências, fraquezas, sua inserção e visibilidade nacional e internacional. Um melhor conhecimento da instituição permite definir estratégias de incentivo, corrigir deficiências e acelerar melhorias.

\section{Referências}

Aljanabi, S. M. e Martinez, I. (1997). Universal and rapid salt-extraction of high quality genomic DNA for PCR-based techniques. Nucleic Acids Research, 25(22), 46924693.

Almeida, E. C. E. e Guimarães, J. A. (2013). Brazil's growing production of scientific articles-how are we doing with review articles and other qualitative indicators?, Scientometrics, 97(2), 287-315.

Irizaga, K. R. D. F. e Vanz, S. A. D. S. (2021). A produção científica por unidade federativa brasileira em ciências agrárias na Scopus: uma análise bibliométrica. AtoZ: novas práticas em informação e conhecimento. Curitiba: Universidade Federal do Paraná, Programa de Pós-Graduação em Gestão da Informação. Vol. 10, n. 1 (jan./abr. 2021), p. 1-14.

Kattge, J., Bönisch, G., Díaz, S., Lavorel, S., Prentice, I. C., Leadley, P., ... e Cuntz, M. (2020). TRY plant trait database-enhanced coverage and open access. Global Change Biology, 26(1), 119-188.

Penteado Filho, R. D. C. e Avila, A. F. D. (2009a). A Scientometric Analysis of Embrapa's Brazil Web of Science Articles from 1977 to 2006. In Proceedings of ISSI (pp. 786-797).

Penteado Filho, R. D. C. e Avila, A. F. D. (2009b). Embrapa Brasil: Análise bibliométrica dos artigos na Web of Science (1977-2006) 2009. Texto para Discussão (Brasília. 1998), v. 36, p. 7-116.

Penteado Filho, R. D. C. e Avila, A. F. D. (2009c). Estudo das citações dos artigos da Embrapa na Web of Science de 1977 a 2006. Texto para Discussão (Brasília. 1998), v. 37, p. 7-131.

Penteado Filho, R. D. C. e Avila, A. F. D. (2010). Reflections on a Scientometrical Analysis of Embrapa Brazil Web of Science Articles from 1977 to 2006. Collnet Journal of Scientometrics and Information Management, 4(1), 9-20. 
Penteado Filho, R. D. C. e Fonseca Júnior, W. C. D. (2017). O problema da padronização das afiliações de autores na base de dados Web of Science: o caso Embrapa e sua solução. Em Questão; v. 23, Edição Especial 5 EBBC, 2017; 74-93.

Turnipseed, S. G., Heinrichs, E. A., Da Silva, R. F. P. e Todd, J. W. (1974). Response of soybean insects to foliar applications of a chitin synthesis inhibitor TH 6040. Journal of Economic Entomology, 67(6), 760-762.

Van Eck, N. J. e Waltman, L. (2010). Software survey: VOSviewer, a computer program for bibliometric mapping. Scientometrics, 84(2), 523-538. 